\title{
Floral Volatiles in Parasitic Plants of the Orobanchaceae. Ecological and Taxonomic Implications
}

\author{
Peter Tóth ${ }^{1,2 *}$, Anna K. Undas ${ }^{1,3}$, Francel Verstappen ${ }^{1}$ and Harro Bouwmeester ${ }^{1}$ \\ ${ }^{1}$ Laboratory of Plant Physiology, Wageningen University and Research Centre, Wageningen, Netherlands, ${ }^{2}$ Department of \\ Plant Protection, Slovak University of Agriculture in Nitra, Nitra, Slovakia, ${ }^{3}$ RIKILT, Wageningen University and Research \\ Centre, Wageningen, Netherlands
}

The holoparasitic broomrapes, Orobanche spp. and Phelipanche spp. (Orobanchaceae), are root parasites that completely depend on a host plant for survival and reproduction. There is considerable controversy on the taxonomy of this biologically and agronomically important family. Flowers of over 25 parasitic Orobanchaceae and a number of close, parasitic and non-parasitic, relatives emitted a complex blend of volatile organic compounds (VOCs), consisting of over 130 VOCs per species. Floral VOC blend-based phylogeny supported the known taxonomy in internal

OPEN ACCESS

Edited by:

Maurizio Vurro,

Institute of Sciences of Food

Production, National Research

Council, Italy

Reviewed by:

Grama Nanjappa Dhanapal, University of Agricultural Sciences,

Bengaluru, India

Lytton John Musselman,

Old Dominion University, USA

*Correspondence:

Peter Tóth

petery@nextra.sk

Specialty section:

This article was submitted to Crop Science and Horticulture, a section of the journal

Frontiers in Plant Science

Received: 27 December 2015

Accepted: 29 February 2016

Published: 15 March 2016

Citation:

Tóth P, Undas AK, Verstappen F and Bouwmeester $H$ (2016) Floral Volatiles in Parasitic Plants of the

Orobanchaceae. Ecological

and Taxonomic Implications.

Front. Plant Sci. 7:312.

doi: 10.3389/fpls.2016.00312 taxonomic grouping of genus and eliminated the uncertainty in some taxonomical groups. Moreover, phylogenetic analysis suggested separation of the broomrapes into two main groups parasitizing annual and perennial hosts, and for the annual hosts, into weedy and non-weedy broomrapes. We conclude that floral VOCs are a significant tool in species identification and possibly even in defining new species and can help to improve controversial taxonomy in the Orobanchaceae.

Keywords: broomrapes, Orobanche, Phelipanche, volatile organic compounds, weeds, taxonomy, floral scents, phylogenetic patterns

\section{INTRODUCTION}

Just as humans and other animals use sound to communicate with organisms in their environment, flowering plants have a sophisticated language for communication, floral scents or floral volatile organic compounds (VOCs). Flowers often emit hundreds of different VOCs and there are large differences between species (Pichersky and Gershenzon, 2002; Raguso, 2008a). These complex blends present a detailed language for communication with other organisms (Dudareva et al., 2006). Floral scent is one of the adaptations that plants have evolved to attract and guide pollinators (Kaiser, 2006; Raguso, 2008b), but VOCs act as a filter at the same time (Junker et al., 2010). The scent of flowers of different species is never the same. This is caused by the large diversity of VOCs and their relative abundance (Knudsen et al., 2004). So far, over 1700 compounds have been identified in floral blends (Knudsen et al., 2006) and one species may emit from one to over a hundred different compounds (Knudsen and Gershenzon, 2006). This implies that the flower VOC blend contains an enormous amount of information (Dudareva and Pichersky, 2006), potentially also on taxonomic relationships. However, only a few studies report on their significance in phylogeny. In male euglossine bee-pollinated orchids, floral fragrance data did not reliably indicate phylogeny (Williams and Whitten, 1999). In two genera of Nyctaginaceae, and in four Licuala species (Arecaceae) flower VOCs did not reflect classification (Levin et al., 2003; Meekijjaroenroj et al., 2007). While phylogenetic relations based on major floral VOCs revealed 
no distinct patterns at higher taxonomic levels (Knudsen et al., 2006), phylogenetic patterns were detected in Cypripedium (Orchideaceae) (Barkman, 2001) and within Nicotiana (Raguso et al., 2006). In the present study we explored the possibilities of using flower VOCs as phylogenetic markers in the taxonomically complicated group of parasitic flowering plants, the broomrapes (Orobanchaceae). These root parasitic plants have significant impact on the ecosystem and often severely reduce host performance (Press and Phoenix, 2005). It has been suggested that the host range and life history of the broomrapes evolved in a concerted fashion (Schneeweiss, 2007) and that the ancestor broomrape had a narrow host range (Manen et al., 2004). However, species with a wide host range have evolved (Parker, 2009), and mostly grow as weeds on annual crops (Rubiales et al., 2009), while the broomrapes in natural ecosystems usually have only one or a few, usually perennial, hosts (Teryokhin, 1997).

The latest monograph of the Orobanche sensu lato (BeckMannagetta, 1930) and current keys (Teryokhin et al., 1993) stress floral characters as species-discriminative characteristics. These morphological traits are difficult to determine (Musselman et al., 1981). Host specificity is therefore often employed as a major factor in classification. To better establish taxonomic relationships various other approaches have been employed. Nuclear rDNA internal transcribed spacer (ITS) sequence data (Wolfe et al., 2005), DNA sequences of $r b c \mathrm{~L}$ (large subunit of the enzyme ribulose-1,5-bisphosphate carboxylase), $n d h \mathrm{~F}$ (NADH dehydrogenase subunit 5), the plastidic rps (ribosomal proteins) (Tank et al., 2006), rps2 (ribosomal proteins 2) (Park et al., 2008), phytochrome A (PHYA) (Bennett and Mathews, 2006) and the low-copy nuclear locus (PHYB) (McNeal et al., 2013) have been used to discriminate genera. Random amplified polymorphic DNA (RAPD) analysis (Román et al., 2003), proteomics (Castillejo et al., 2009), amplified fragment length polymorphism (AFLP) analysis (Vaz Patto et al., 2009), more detailed plastid $r b c \mathrm{~L}$ sequencing (Manen et al., 2004) and nuclear ITS sequences (Schneeweiss et al., 2004; Carlón et al., 2005, 2008) were employed to discriminate species. Only the last three studies dealt with the Old World Orobanche genus as a whole. It was split into an Orobanche and a Phelipanche genus. Nevertheless the phylogenetic relationships remain still insufficiently understood and controversial (Park et al., 2008).

The present study offers insight into the floral scent chemistry of Orobanchaceae. We used ultra-sensitive, unbiased, floral headspace metabolite profiling and advanced data-analysis and statistical methods normally applied in metabolomics. The floral volatile blends of 32 species from the root parasitic plant genera Orobanche, Phelipanche, Boulardia, Cistanche, Striga, and parasitic outgroup Cynomorium as well as the non-parasitic but related species from the genera Antirhinum, Mimulus, and Paulownia were analyzed and the VOC data used to infer taxonomic relationships. The results are compared with previously established phylogenetic relationships as based on taxonomic considerations or molecular markers.

We show that the analysis of the floral chemistry is a reliable to infer phylogenetic relationships within the Orobanchaceae as we can confirm relationships established based on other approaches. Moreover, our study highlights a number of disputed and/or unreliable phylogenetic relationships. We argue that floral scent can be used to distinguish species, which are difficult to discern based on morphological traits. Finally, our analysis suggests separation of the broomrapes into two different groups, of species growing on annual and short lived perennial hosts and species growing on perennial hosts, suggesting the correlation between VOC profiles and host features.

\section{MATERIALS AND METHODS}

\section{Plant Material}

A total of 32 plant taxa were screened for floral VOCs. We focused on the two most important genera of Orobanchaceae, Orobanche (16 species) and Phelipanche (4 species). Other parasitic broomrapes from genera Cistanche (2 species), and Boulardia (1 species), and non-broomrape (but Orobanchaceae) parasitic species, Striga spp. (3 species) were included as well. In addition, six outgroup species, one non-Orobanchaceae parasitic Cynomorium sp. (1 species) and five closely related non-parasitic species, Antirrhinum spp. (2 species), Mimulus spp. (2 species), and Paulownia sp. (1 species) were used (see Supplementary Table S1). Of all species more than five samples were used for headspace collection as some samples, especially in the field, were influenced by water or had poor signal intensity. As it is difficult or sometimes impossible to cultivate some of the broomrapes under greenhouse conditions, VOCs of 18 broomrapes were trapped under natural conditions in situ. Four of them, Orobanche alba, O. caryophyllacea, O. flava, and O. reticulata were checked in different locations and O. lutea in two different years. These are referred to within figures and tables using numbers, e.g., O. alba 1, O. alba 2 (Supplementary Table S1). The remaining 14 species were grown under greenhouse conditions as described by Kroschel (2001). The seeds were sown in a soil-sand mixture $3: 1$ in a top layer of approximately $3-10 \mathrm{~cm}$ deep. The seed density was $10 \mathrm{mg} / \mathrm{L}$ of soil. To break dormancy the pots with the broomrape seeds were watered daily with $60 \mathrm{ml}$ of water, during 12 days at $16 \mathrm{~h}$ light $/ 8 \mathrm{~h}$ dark, $21 / 18^{\circ} \mathrm{C}$, and $60 \%$ relative humidity (Matúšová et al., 2004). Subsequently, germinated host plant seeds were introduced to the pots and watered daily for 5 days, after which the watering regime was changed to three times per week until broomrapes flowered. The same conditions were used for non-parasitic plants. For more details about the species used in this study see Supplementary Table S1.

\section{Headspace/VOC Trapping}

The VOCs emitted by flowers were collected using dynamic headspace sampling as described by Kappers et al. (2010). Two or three flowering shoots (=plants) or only flowers (in the case of non-parasitic plants) were cut, placed into vials filled with water and immediately transferred to a glass jar $(720 \mathrm{ml})$, which was tightly closed with a Teflon lid with an in- and outlet. Air was drawn from the jar through a stainless steel cartridge (Markes, Llantrisant, UK) containing $200 \mathrm{mg}$ Tenax TA (20/35 mesh; Grace-Alltech, Breda, The Netherlands) and the incoming air was purified by passing through a similar cartridge containing Tenax. In the field the air was drawn off 
the jar using the portable PAS-500 Micro Air Sampler (Supelco, Sigma-Aldrich) with Low Flow Orifice and in the greenhouse using electric pumps (ADC, The Analytical Development Co Ltd, Hoddesdon, England). The air flow was controlled by a flow controller (Brooks Instr. Veenendaal, The Netherlands) which was set to approximately $100 \mathrm{ml} \mathrm{min} \mathrm{m}^{-1}$. VOCs were trapped for $5 \mathrm{~h}$, mostly in the morning from 9:30. Four to six collections and its respective control (empty glass jar) were made simultaneously. After sampling, the Tenax cartridges were capped and stored under room temperature until analysis.

\section{Gas Chromatography - Mass Spectrometry (GC-MS) Headspace Analysis}

Analysis of the trapped volatiles was performed as described by Snoeren et al. (2010) with some modifications on a Trace Ultra GC coupled to a Thermo Trace DSQ quadrupole Mass Spectrometer (Interscience, The Netherlands). Control samples (blank Tenax cartridges) were used to disqualify any nonbiological compounds during each GC run. Trapped VOCs were released from the Tenax by heating the cartridge at $250^{\circ} \mathrm{C}$ for $4 \mathrm{~min}$ with a helium flow of $30 \mathrm{ml} \mathrm{min}^{-1}$ and re-trapped on a multi-bed sorbent at $10^{\circ} \mathrm{C}$. By heating this sorbent, the compounds were injected into a capillary column (RTX-5MS, $30 \mathrm{~m}, 0.25 \mu \mathrm{m}$ id, $1.4 \mu \mathrm{m}$ df, Restek, Interscience, The Netherlands). The GC temperature program started at $60^{\circ} \mathrm{C}$ (hold for $2.5 \mathrm{~min}$ ) and rose to $250^{\circ} \mathrm{C}$ at $12^{\circ} \mathrm{C} \mathrm{min} \mathrm{m}^{-1}$ (hold for $1.5 \mathrm{~min}$ ) with a column flow of $1 \mathrm{ml} \mathrm{min}{ }^{-1}$. The column effluent was ionized by electron impact ionization at $70 \mathrm{eV}$. Mass spectra were collected over the mass range $\mathrm{m} / \mathrm{z} 35$ to 300 at a scan rate of three spectra $\mathrm{sec}^{-1}$. The chromatography and spectral data were evaluated using Xcalibur software (v. 2.0.7, Thermo Fisher Scientific Inc.). Compounds were annotated by comparing the mass spectra with mass spectral libraries (Wiley 7th edition and NIST08), and by comparing calculated retention indices with those given by NIST08, Adams (2007) and El-Sayed (2012). The annotation of many compounds was verified using an in house developed mass spectra/RI library. Any suspicious compounds (e.g., benzene, toluene, 1,4-dichlorobenzene) were carefully checked in the literature and in The Pherobase (El-Sayed, 2012) for known biological properties and occurrence in other plants, to be accepted as flower VOCs or at least potential volatiles as there are no data about in connection with broomrapes in the literature.

\section{Data Analysis}

Prior to statistical analysis the entire set of chromatograms was baseline corrected and aligned using Metalign software version 010110 (Lommen, 2009). Masses that were present in less than 5 samples and had a signal below 100000 were removed using an in-house script called MetAlign Output Transformer (METOT; Plant Research International, Wageningen, The Netherlands) and mass spectra reconstituted using MsClust (Tikunov et al., 2005). In this way Metalign output was reduced from 16366 mass peaks to 639 putative compounds. Non-biological chemicals were traced using Xcalibur software (v. 2.0.7, Thermo Fisher Scientific Inc.) and removed from the dataset. Samples that were too much influenced by polysiloxanes (column related compounds with $\mathrm{m} / \mathrm{z} 207,267,355$, etc.) or water, or had poor quality (signal intensity) were excluded from the dataset. Data, peak intensities obtained after Metalign were ${ }^{2} \log$ transformed and the mass signals normalized by subtraction of the average peak height of all signals of that mass across all samples from each individual signal for that mass (mean centering). Principal component analysis (PCA) was performed on compounds whose peak heights were significantly different between taxa $(P<0.05$ as determined using ANOVA) using GeneMath XT (v. 2.12, Applied Maths NV, Belgium). Hierarchical clustering analysis (HCA) with 10000 bootstrap re-samplings was performed in $\mathrm{R}$ (v. 2.10.1; R Development Core Team) following Shimodaira (2004).

\section{RESULTS}

\section{Floral Scent Chemistry}

Dynamic headspace sampling was performed either in the greenhouse or headspace collection chamber (14 plant species) or in the field (18 species). All the headspace samples (at least five per species) of the 32 plant species (Supplementary Table S1) were analyzed using GC-MS. The entire GC-MS dataset allowed the detection of 639 compounds of which 482 were significantly different between any of the species analyzed. Most of these compounds could be (putatively) identified. These data are completely novel as this is the first report of VOCs for any holoparasitic Orobanchaceae. The significantly different metabolites were used for further analysis using unsupervised PCA. For four Orobanche spp. (O. alba, O. elatior/Figure 1A/, O. flava, and O. reticulata), two Phelipanche spp. (Ph. aegyptiaca and $P h$. ramosa/Figure $1 \mathrm{~F} /$ ) and two outgroup species (Mimulus luteus and Paulownia tomentosa) a detailed annotation of the floral VOCs is shown in Supplementary Table S2. In these six broomrapes, 393 VOCs could be tentatively identified, and although each species was characterized by a different VOC composition, there was also considerable overlap (Supplementary Table S2). A total of 59 from 278 metabolites were present in the blend of all four Orobanche spp., 95 from 219 compounds were present in both Phelipanche spp. and 43 VOCs were common in all six broomrapes shown in Supplementary Table S2. The Phelipanche spp. emitted about 13\% more VOCs than the Orobanche spp. Floral scents of outgroup species represented rather simple blends in comparison with broomrapes, containing only from 66 (M. luteus) to 71 compounds ( $P$. tomentosa) (Supplementary Table S2). Spectrum of VOCs across all 20 holoparasitic broomrape species (Orobanche spp. and Phelipanche spp.) was very rich and unusually diverse, including representatives of at least 12 functional groups: alcohols, aldehydes, amines, hydrocarbons (including monoterpenoids and sesquiterpenoids), aromatic hydrocarbons, carboxylic acids, esters, furans, ketones, phenols, sulfur compounds, and diverse functional groups. Many 

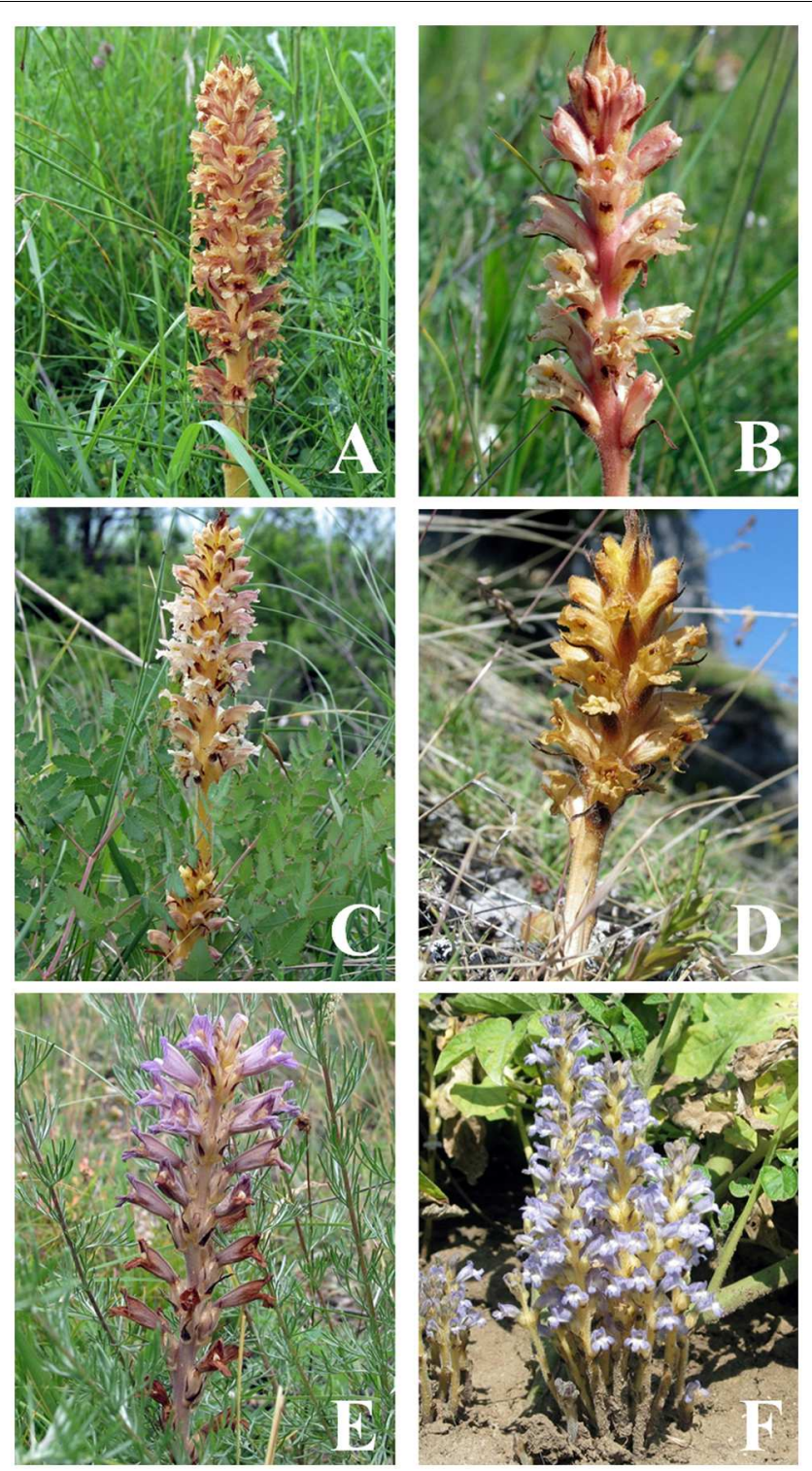

FIGURE 1 | Examples of some morphologically, taxonomically, and evolutionary difficult to distinguish broomrape species, (A) Orobanche elatior, (B) Orobanche kochii, (C) Orobanche alsatica, (D) Orobanche mayeri, (E) Phelipanche arenaria, and (F) Phelipanche ramosa.

compounds are known as semiochemicals with behavioral function (e.g., kairomones, attractants, and pheromones). Each species has its own characteristic VOCs profile. However, 40 compounds were presented in the scent of all 20 broomrapes studied (Supplementary Table S3). These mutual compounds were strongly dominated by hydrocarbons, which represented $37.5 \%$ of them, followed by aldehydes (17.5\%), alcohols (15\%), aromatic hydrocarbons (10\%), ketones (10\%), esters (5\%), carboxylic acids (2.5\%), and diverse functional groups (2.5\%). Certain compound, as acetone, toluene, pentanal, dibutyl phthalate, 4-methylpentan-2-one, and many others within broomrape VOCs are unusual, however, already known from plants. The striking exception within mutual compounds features pentane-2,4-dione and 2-decen-1ol which are known from no other plants so far. Very characteristic chemicals for most of broomrapes (except, e.g., Ph. aegyptiaca) are also isopropyl tetradecanoate and isopropyl hexadecanoate. There are many other interesting compounds emitted by broomrapes. Scent of some broomrapes is aromatic, e. g., strong clove-like odor of O. alba brings on 4-ethylguaiacol and 4-vinylguaiacol, very strong fusel-like smell of $O$. foetida causes tetradecane and tetradecanal, and earthy, mushroom fragrance of $\mathrm{Ph}$. aegyptiaca is result of benzyl tiglate emission.

\section{Floral Scent Relations and Clustering}

In order to assess the total variation in the whole dataset of all species, the volatile profiles were analyzed by principal component analysis (PCA). PCA clearly showed the species differences in VOC composition, clustering the 32 species into separate groups, with the replicate samples of each species usually clustering close together (Figure 2). This is remarkable and demonstrating the reproducibility of our collection and analysis methods as some of the species were sampled in different locations and years. There was no or just negligible effect of trapping location on relative emission of VOCs. See for example O. alba 1-2, O. flava 1-4, O. caryophylacea 12, O. reticulata 1-2 (Figure 2 ). Also the year of sampling did not affect the volatile profile. See for example O. lutea 1-2 (Figure 2).

The first three principal components (PCs) explained 25.6\% of the observed variation in the VOCs while the first six PCs explained 39.6\%. All analyses resulted in two distinct and highly supported groups. Broomrapes growing on perennial hosts (Figure 2, left side) clearly separated from the rest of the broomrapes growing on annual and short-lived perennial hosts as well as other parasitic plant species and non-parasitic plants (Figure 2, right side). The non-Orobanche parasitic Boulardia latisquama, and non-parasitic P. tomentosa, Antirhinum majus nanum, $A$. majus pumilum, and $M$. cardinalis clustered separately from each other and as group in between the parasitic annual host Orobanche (O. cernua, O. cumana, O. foetida, O. minor), Phelipanche (Ph. aegyptiaca, Ph. mutelii, Ph. ramosa) and Striga spp. (S. asiatica, S. gesnerioides, S. hermonthica). Non-parasitic $M$. cardinalis clustered closely with the nonbroomrape parasitic S. hermonthica. Other non-broomrape parasitic species (Cistanche phelypaea, Cynomorium coccineum) cluster separately from most broomrapes but are quite similar (Figure 2). Hierarchical clustering analysis (HCA) showed that the Phelipanche species - with a remarkable exception for $P h$. arenaria - share the same clade with the non-parasitic $A$. majus nanum, A. majus pumilum, $M$. cardinalis, and $P$. tomentosa (Figure 3). O. cumana and O. cernua cluster together with the non-broomrape parasitic species $B$. latisquama and $C i$. phelypaea. O. foetida groups with the non-broomrape parasitic species Cy. coccineum and $O$. minor with the witchweeds (Striga spp.) and the non-parasitic M. luteus (Figure 3). The Approximately Unbiased $P$-value (AU, lower red numbers), obtained using Pvclust (a better approximation for reliability 


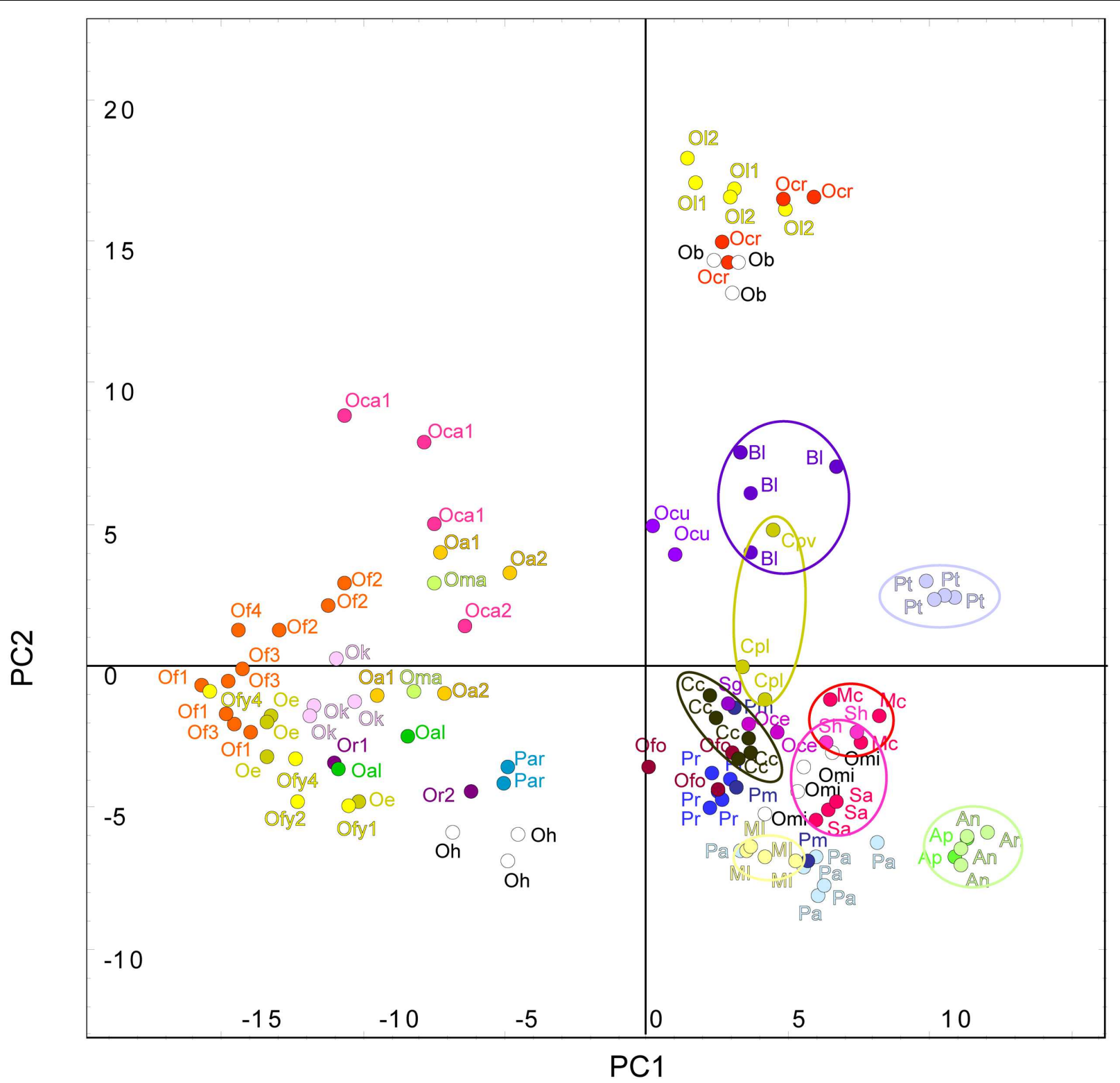

FIGURE 2 | Principal component (PC) analysis of the floral blends of the $\mathbf{3 2}$ species studied. Principal component analysis (PCA) was done with compounds showing a significant difference between the species ( $P<0.05$ from ANOVA test) and it was performed by GeneMath XT. Letters and symbols represent single species. An, Antirrhinum majus nanum; Ap, A. majus pumilum; BI, Boulardia latisquama; Cpl, Cistanche phelypea (lutea); Cpv, Ci. phelypea (violacea); Cc, Cynomorium coccineum; Mc, Mimulus cardinalis; MI, M. Iuteus; Oa1, Oa2, Orobanche alba (location 1, 2); Oal, O. alsatica; Ob, O. ballotae (white color); Oca1, Oca2, O. caryophylacea (location 1, 2); Oce, O. cernua; Ocr, O. crenata; Ocu, O. cumana; Oe, O. elatior; Of1-Of4, O. flava (location 1,2,3,4), Ofy1,2,4, O. flava yellow morph (location 1,2,4); Ofo, O. foetida; Oh, O. hederae (white color); Ok, O. kochii; Ol1, OI2, lutea (year 1,2); Oma, O. mayeri; Omi, O. minor (white color); Or1, Or2s, O. reticulata (location 1,2); Pa, Phelipanche aegyptiaca; Par, Ph. arenaria; Pm, Ph. mutelii; Pr, Ph. ramosa; Pt, Paulownia tomentosa; Sa, Striga asiatica; Sg, S. gesnerioides; Sh, S. hermonthica.

of clustering than the Bootstrap Probability $P$-value; BP, upper green numbers) shows that most clusters within the data set are reliable and significant (Figure 3). In order to explore how robust the clustering is, we analyzed the stability of the clustering after modifying the dataset. HCA on smaller subsets (e.g., without non-parasitic plants) resulted in the very similar output as the whole dataset (Figure 4). Figure 4 shows that broomrapes growing on perennial hosts are further subdivided into a cluster containing the genus Orobanche and a cluster containing the genus Phelipanche, section Arenariae (bottom Figure 4). The same is true for the annual host broomrapes, where the genus Phelipanche, section Phelipanche is markedly separated from the genus Orobanche (top Figure 4). Based on the VOC data, Orobanche and Phelipanche are not monophyletic groups (taxon forming a clade). 


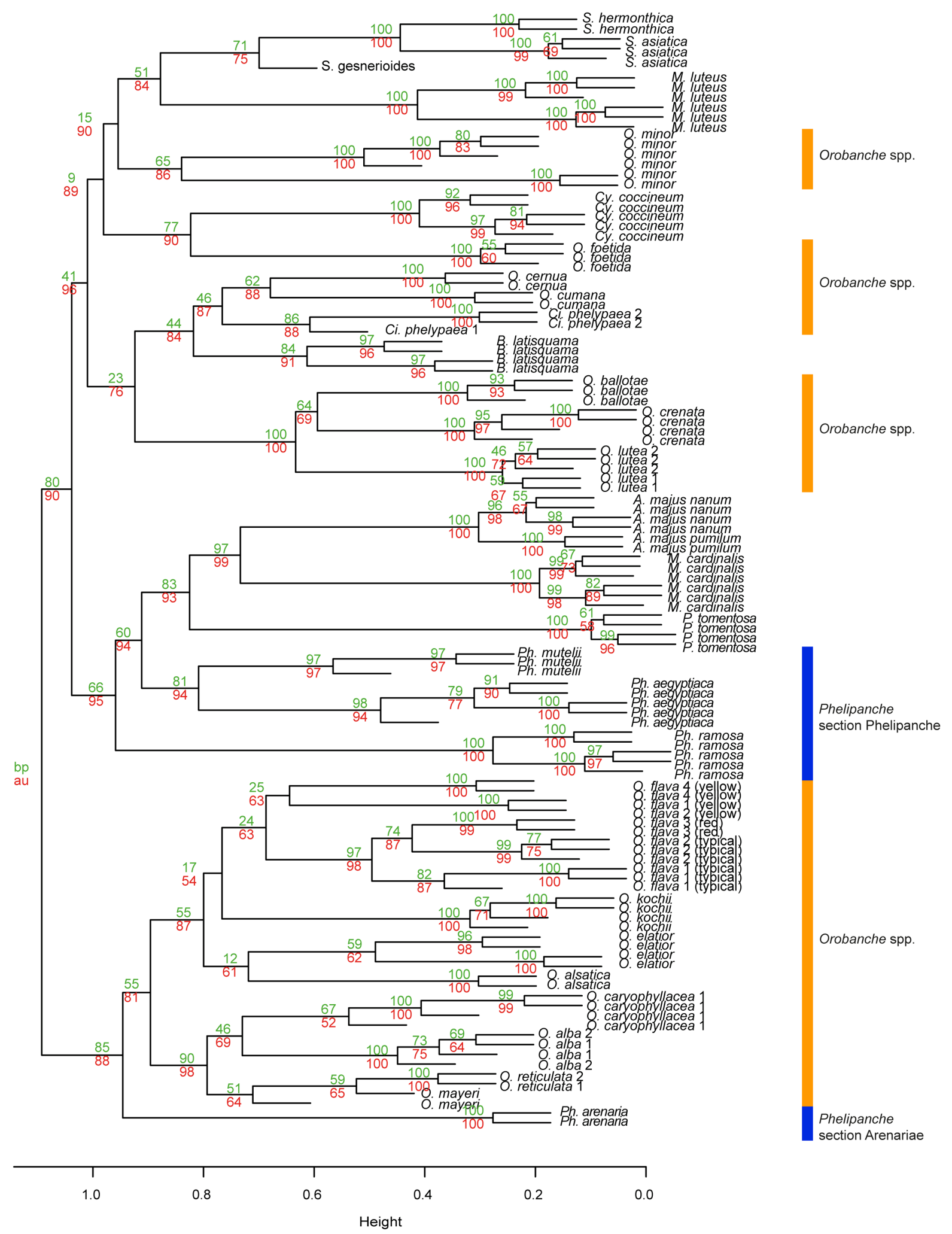

FIGURE 3 | Hierarchical clustering diagram of the flower VOC profiles of 32 species studied. HCA was performed with R and based on PCA of significantly different flower blends. Numbers at nodes are bootstrap probability $P$-value (BP, upper green numbers) and approximately unbiased $P$-values (AU, lower red numbers). The definition of the two genera of Orobanche is designated in orange (genus Orobanche) and blue (genus Phelipanche) bar; section Arenariae is also indicated (subsections within genus Orobanche are shown in Figure 6). 


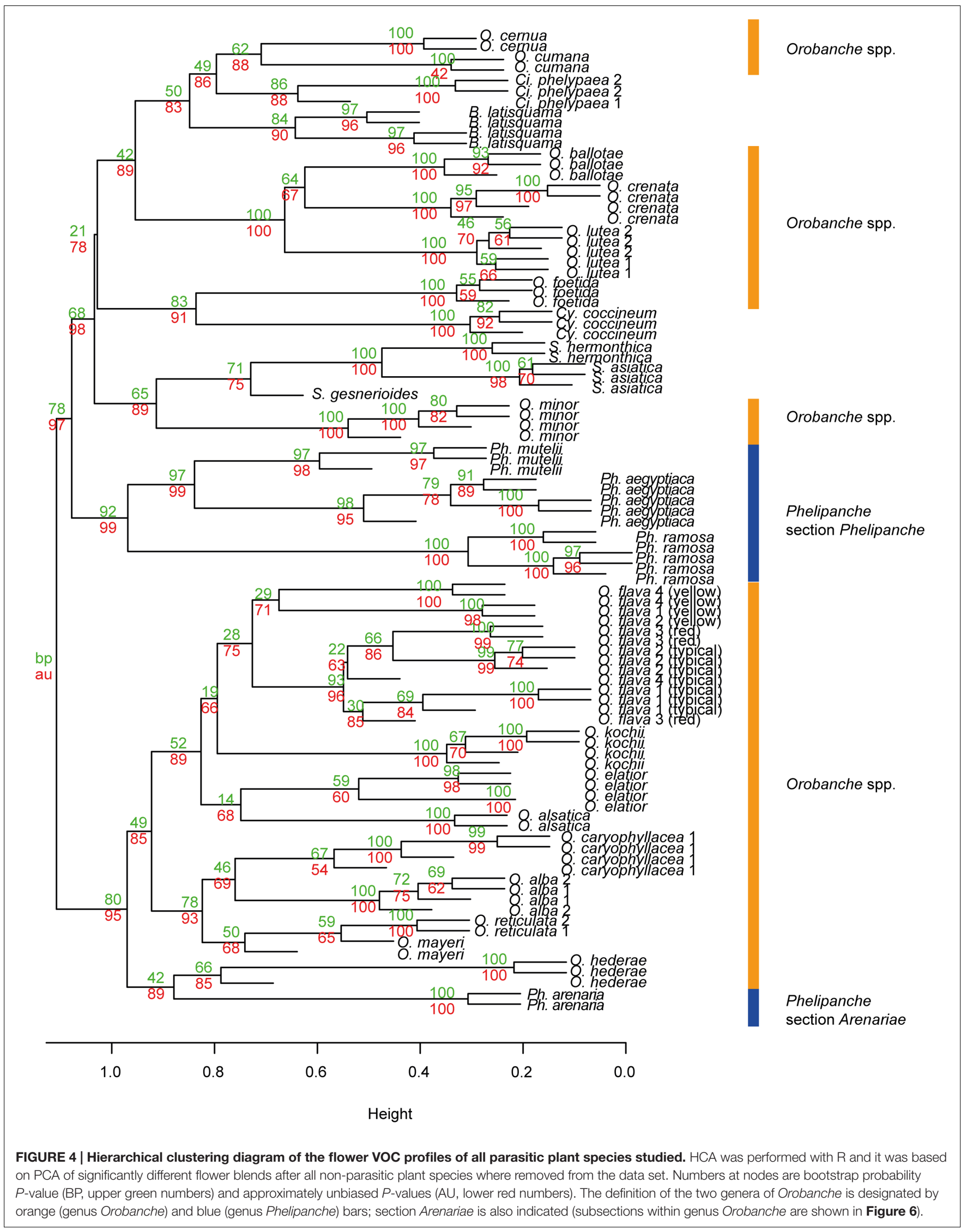




\section{Phylogenetic Patterns within the Broomrapes}

To visualize the phylogenetic relationships between the broomrapes in more detail, PCA was done on the VOC data of Phelipanche and Orobanche using Boulardia as an outgroup (Figure 5). The broomrapes were divided along the first PC (explaining $11.2 \%$ of the variation) into two groups, the perennial-host- and the annual-host-broomrapes. The first group comprises species exclusively growing in the wild; the second group comprises mostly weedy broomrapes. The statistically well supported position of Ph. arenaria (between Orobanche spp.) is particularly surprising. The annual-host broomrapes are subdivided into two groups along the second PC (explaining $19.8 \%$ of variation) into a cluster containing the aromatic (=strong fragrant VOC blend) weedy species $O$. crenata, O. lutea, and the non-weedy and aromatic O. ballotae and a cluster containing all other weedy species of the genera Orobanche (O. cumana, O. cernua, O. minor, O. foetida) and Phelipanche (Ph. aegyptiaca, Ph. mutelii, Ph. ramosa)
(Figure 5). Figures 6 and 7 illustrate the association of host specificity and host life history on phylogenetic relationships. The weedy cluster comprises almost exclusively species growing on annuals or short-lived perennial hosts. Most of these species are weeds in agriculture, except $O$. ballotae and B. latisquama. The latter is growing on a perennial host. Boulardia is not, but was in the past regarded to be an Orobanche spp., so we included it here as a closely related out-group. The host range of the weedy group ranges from monophagy (O. ballotae, O. cumana, O. lutea) through broad oligophagy (O. cernua, O. foetida,) to polyphagy (O. crenata, O. minor, Ph. aegyptiaca, Ph. mutelii, Ph. ramosa,). The typical feature of wild species is monophagy (O. elatior, $O$. hederae, O. kochii/Figure $\mathbf{1 B} /$, Ph. arenaria/Figure $\mathbf{1 E} /$ ) or narrow oligophagy (O. alsatica/Figure $1 \mathrm{C} /$, O. flava, O. alba, O. caryophyllacea, O. reticulata, Orobanche mayeri/Figure 1D/) (Figures 6 and 7). In general, the hierarchical clustering of the genera Orobanche and Phelipanche reflects the known taxonomy especially in internal taxonomic grouping of genus (subsections). Distribution and composition of the minor clades was very

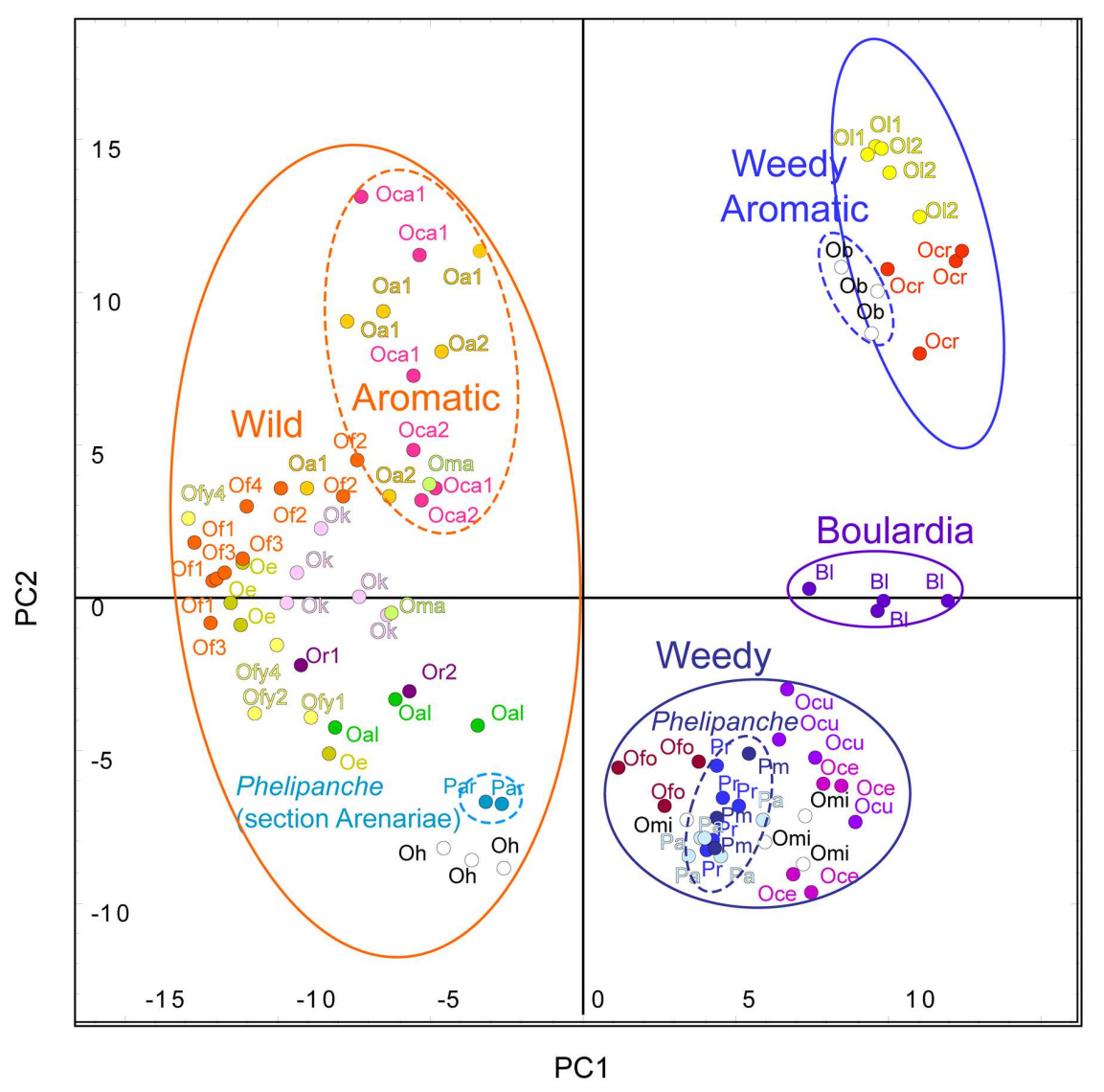

FIGURE 5 | Principal component analysis of the floral blends of the 21 European broomrapes studied (including Boulardia latisquama). PCA was done with compounds showing a significant difference between the species $(P<0.05$ from ANOVA test) and it was performed by GeneMath XT on a data subset with broomrapes only. Letters and symbols represent single species. Group of wild broomrapes: Oa1, Oa2, Orobanche alba (location 1, 2), Oal, O. alsatica; Oca1, Oca2, O. caryophylacea (location 1, 2); Oe, O. elatior; Of1-Of4, O. flava (location 1,2,3,4); Ofy1,2,4, O. flava yellow morph (location 1,2,4); Oh, O. hederae (White color); Ok, O. kochii; Oma, O. mayeri; Or1, Or2, O. reticulata (location 1,2); Par, Phelipanche arenaria. Group of weedy broomrapes: Ob, O. ballotae (White color); Oce, O. cernua; Ocr, O. crenata; Ocu, O. cumana; Ofo, O. foetida; Ol1, Ol2, O. lutea (year 1,2); Omi, O. minor (White color); Pa, Ph. aegyptiaca; Pm, Ph. mutelii; Pr, Ph. ramosa. Other broomrapes: BI, Boulardia latisquama. 


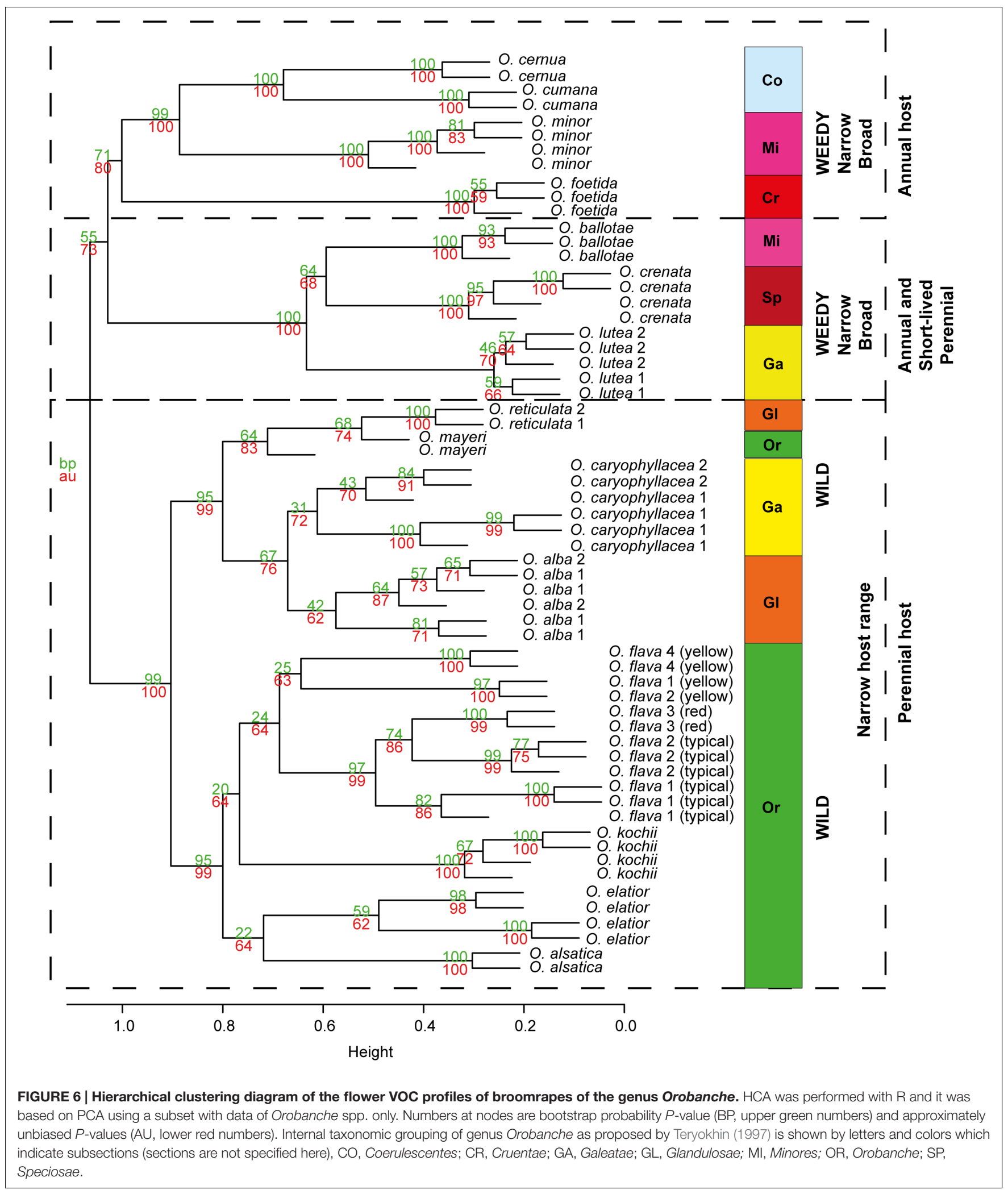

stable in all cluster analyses performed. Two highly supported clades in the genus Orobanche within the wild group were discriminated (bottom half of Figure 6). The first clade (BP/AU
95/99) involves the species from three subsections, Glandulosae (O. alba and O. reticulata), Orobanche (O. mayeri), and Galeatae (O. caryophyllacea). The former two, however, did not cluster 


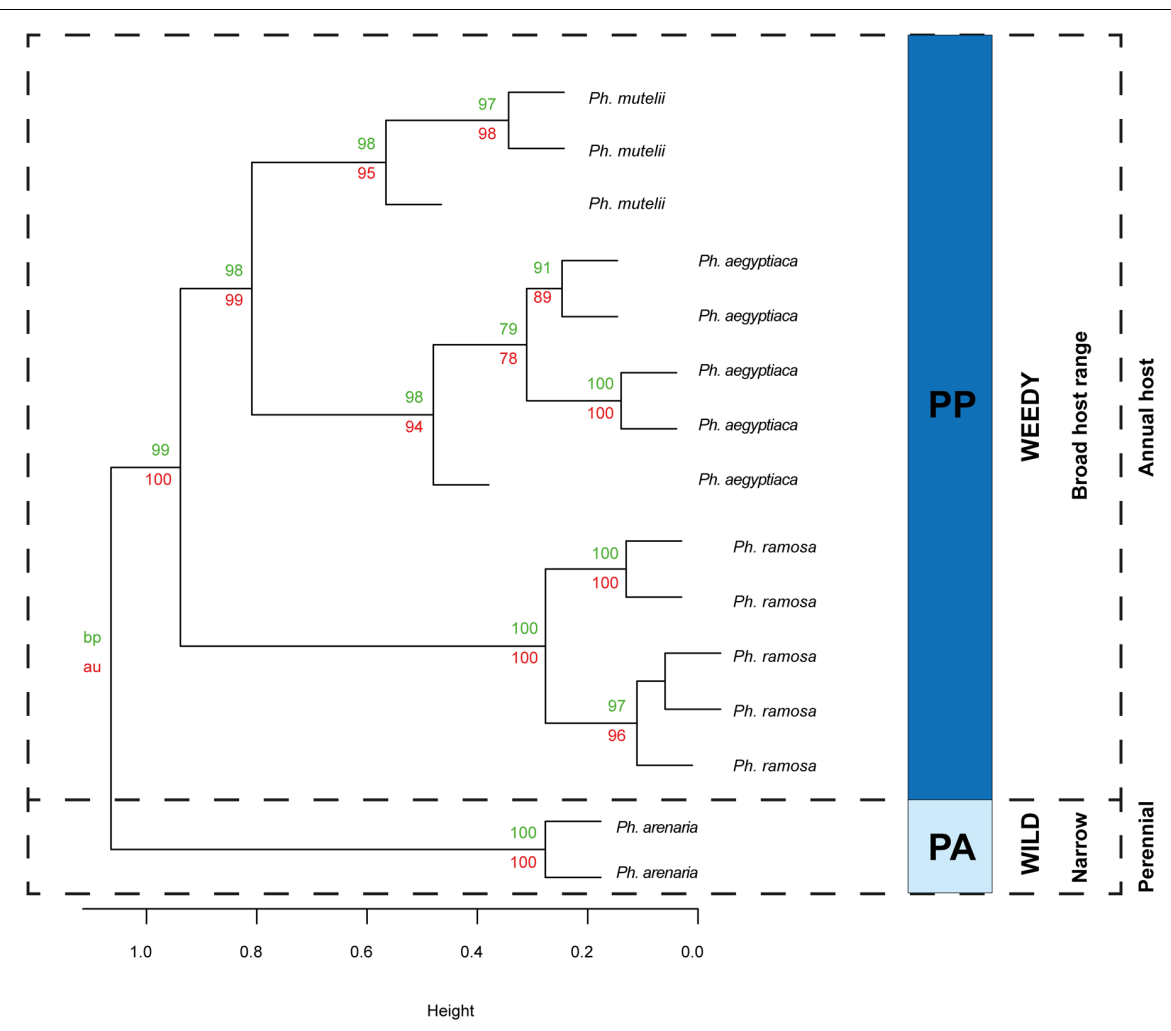

FIGURE 7 | Hierarchical clustering diagram of the flower VOC profiles of all broomrapes of the genus Phelipanche. HCA was performed with R and it was based on recalculated PCA using a subset with data of Phelipanche spp. only. Numbers at nodes are bootstrap probability $P$-value (BP, upper green numbers) and approximately unbiased $P$-values (AU, lower red numbers). Taxonomic grouping of the genus Phelipanche as proposed by Teryokhin (1997) is shown by letters and colors which indicate sections, PP, Phelipanche and PA, Arenariae.

separately, since O. mayeri clustered closely with O. reticulata. The second clade (BP/AU 95/99) represents a monophyletic group and matches with the subsection Orobanche. In this clade, O. kochii is closer related to O. flava and more distant from O. elatior, which is closer to O. alsatica. Interestingly, O. mayeri (mentioned above) differed markedly from the morphologically difficult to assign $O$. alsatica aggregate, where it taxonomically belongs! Unexpectedly the yellow morph of O. flava clustered separately from the other color morphs of the well supported O. flava clade (Figure 6). Three well supported clades in the genus Orobanche were present in the weedy group (top half of Figure 6). One of these is the cluster of three aromatic species with differing taxonomy, O. lutea (Galeatae), O. crenata (Speciosae), and O. ballotae (Minores). Two further clades observed were the basal lineage corresponding to O. foetida (Cruentae) and the lineage with O. minor (Minores), and O. cumana and O. cernua (Coerulescentes). The separate clustering of $O$. minor was statistically sufficiently supported and was clearly separate from O. cumana and O. cernua. The latter two were also distinct from each other (Figure 6). Weedy species of the genus Phelipanche (section Phelipanche) clustered together well supported within the weedy cluster (Figure 7). Within this cluster, Ph. mutelii and Ph. aegyptiaca constitute one clade and $P h$. ramosa relatively isolated another. The most distinct species $P$. arenaria (section Arenariae) clustered completely separate from the other Phelipanche spp. within the wild broomrape group (Figures 4 and 7), and constitutes a separate lineage either alone (Figure 3) or together with $O$. hederae (Figure 4).

\section{Synapomorphic Characters}

Using Xcalibur software, we identified which VOCs are differentially emitted by species within the wild and the weedy clusters. Since these potential synapomorphic characters (shared, newly evolved features) could carry phylogenetic information, mapping the presence and absence of VOCs was realized in all 21 European broomrapes (including Boulardia and excluding Cistanche). Out of the 544 VOCs considered, two compounds, 2,3-butanediol and phytone (hexahydrofarnesyl acetone) were unique to the weedy species only. Species from the genera Phelipanche [except Ph. arenaria (!)] emitted both. 2,3-Butanediol occurred in the weedy group O. cumana, O. cernua, O. minor, O. foetida, $O$. ballotae, and non-broomrape B. latisquama and phytone occurred also in the weedy O. minor, O. cumana, and O. cernua. On the other hand, the sesquiterpene aristolene was exclusively emitted by Orobanche spp. with the exception O. cumana and O. cernua. 2-methylpropan-1-ol and the monoterpenoid eucalyptol were common VOCs in most 
Orobanche spp. and Ph. arenaria but they were absent in the weedy species.

\section{DISCUSSION}

\section{Phylogenetic Patterns within Broomrapes}

A number of authors have reported on failed efforts to use floral scent chemistry for phylogenetic analysis (Williams and Whitten, 1999; Levin et al., 2003; Meekijjaroenroj et al., 2007) and as far as we know only two studies have yielded credible phylogenetic patterns (Barkman, 2001; Raguso et al., 2006). One possible explanation is that the number of species and especially the number of VOCs used in the studies that failed was quite low. The number of VOCs we have collected exceeds that of previous studies. The differences reflect probably unusually high scent diversity found in broomrapes and the high sensitivity due to thermal desorption. Our metabolomics approach enabled the use of the more complete VOC profile. Together this may have been decisive in generating sufficient data to allow for reliable statistical analysis and hence reliable phylogeny. The chemical and statistical analysis of the floral VOCs of 23 European broomrapes (including Boulardia and Cistanche) resulted in phylogenetic relationships that are offering new insights into broomrape phylogeny that can be tested with independent phylogenetic analyses. The key difference, in comparison with phylogenetic relations inferred from taxonomical (BeckMannagetta, 1930; Teryokhin, 1997) or recent molecular studies (Román et al., 2003; Manen et al., 2004; Schneeweiss et al., 2004; Schneeweiss, 2007; Park et al., 2008), is the separation of broomrapes into two main groups, a weedy (growing on annual and short lived perennial hosts) and a wild (growing on perennial hosts) group.

The clades now recognized are based on functional traits, such as host range and life history, but these clades are not easily diagnosed using morphological characters. It has been hypothesized that the host range and life history of broomrapes evolved in a correlated fashion (Schneeweiss, 2007). Our floral scent analyses underline that specialization for the type of host plant is indeed very likely the driving force of evolution within the broomrapes (Figures 6 and 7). However, also evolution of weediness seems to be an important driving force in speciation in the Orobanche and Phelipanche genera. Weedy broomrapes were placed into two independent phylogenetic clusters within the genus Orobanche (O. cumana group and O. crenata group), and into one within the genus Phelipanche (Figures 6 and 7). This suggests that weediness originated several times independently during the evolution of the broomrapes.

The level of host specialization (monophagy, oligophagy, polyphagy) seems to be less significant for the phylogenetic patterns than the host lifestyle (annual or perennial). For instance, in the group of weedy species of the genus Orobanche, host specialization ranges from monophagy (O. cumana - weedy forms on sunflower but wild forms on Artemisia spp.), through oligophagy (O. cernua - weedy forms on Solanaceae and wild forms on Artemisia spp. and some other Asteraceae) up to polyphagy (O. minor various families) (Teryokhin, 1997). A similar situation occurs within the aromatic weedy species. O. crenata is a typical polyphagous species (Parker, 2009), O. lutea ranges from monophagy to oligophagy (Teryokhin et al., 1993; Piwowarczyk and Krajewski, 2014), while the non-weedy O. ballotae is strictly monophagous (Pujadas Salva, 1997) (Figure 6).

Support for life history of the host plant being a driving force in broomrape evolution and hence phylogeny is provided by species from the subsections Orobanche, Galeatae, and Minores. All species of the subsection Orobanche grow on perennial hosts, share one monophyletic clade with the exception O. mayeri, and all clusters just as expected based on the known taxonomical subsection structure (Teryokhin et al., 1993; Teryokhin, 1997). However, the other two subsections show clustering that is not consistent with existing taxonomy (Figures 3, 4 and 6). Such discordance has been also identified before by molecularphylogenetic clades based on a broader species sampling (Manen et al., 2004; Schneeweiss et al., 2004). This is, for example, clear in the subsection Minores (Beck-Mannagetta, 1930) (Figures 2 and 5). Minores species $O$. minor groups with weedy species that grow on annual hosts, $O$. ballotae together with aromatic weeds on short-lived perennials, whereas $O$. hederae shares a clade with $\mathrm{Ph}$. arenaria and both are growing on perennial hosts (Figure 4). Our data support Teryokhin et al. (1993) rather than Beck-Mannagetta (1930). For instance O. hederae placement in a separate subsection Hederae and not together with the rest of Minores is highly supported by our study. Phylogenetic hypotheses based on DNA sequence data also suggested the presence of heterogeneity in the $O$. minor clade (Schneeweiss, 2007). We propose that this unclear phylogeny can be resolved by using floral scents. Our data verified and supported also known morphological (Teryokhin et al., 1993) and molecular (Schneeweiss et al., 2004; Park et al., 2008; Castillejo et al., 2009) distinctions between the sections Phelipanche and Arenariae, and this were statistically supported here. Besides VOCs data placed interestingly Phelipanche within Orobanche (Figures 3 and $\mathbf{4}$ ).

Figure 5 shows B. latisquama (syn. Orobanche macrolepis) as a phylogenetically clearly independent group, as was also concluded by Schneeweiss et al. (2004). On the other hand B. latisquama and Ci. phelypea are clearly part of the O. cumana lineage within the weedy broomrape group (Figures 3 and 4 ). The genus Paulownia has been placed in a clade with Orobanchaceae and Phrymaceae (Tank et al., 2006). This placement was confirmed also here (Figures 2 and 3). Surprisingly, P. tomentosa, a tree native to China, M. cardinalis (Phrymaceae) of North American origin, and Antirrhinum spp. (Veronicaceae) of Eurasian origin clustered together in the weedy Phelipanche spp. clade. This could point to a New World origin for Phelipanche, in contrast to the likely Old World Orobanche (Schneeweiss et al., 2004). The latter shared a mutual clade with the parasitic Striga spp. (Figure 3). S. hermonthica and S. asiatica, both with host preference for tropical cereal crops, grouped closely together, while $S$. gesnerioides parasitizing fabaceous host species clustered separately from the two cereal parasites. 
The presence of aromatic VOCs can provide additional support for clades (Levin et al., 2003). Aromatic species were found in three different clusters, the O. foetida, O. lutea, and O. caryophylacea groups (Figures 3, 4, and 6). The strong aromatic odor seems to be related to the typical habitat open, sunny, and warm with abundant insect fauna - of these broomrapes. However, the very distinct scent of these aromatic broomrapes does not result in high insect diversity on the rewarding broomrape flowers (Tóth pers. obs.). Possibly, the strong fragrance acts as plant defense rather than pollinator lure as also demonstrated for aloe nectar (Johnson et al., 2006).

\section{Species Determination}

In our study, the broomrapes are generally well differentiated by their floral scents and the samples of single species, even of individuals from different locations or years, clearly group together (Figures 3, 4, and 6). As it is often unclear to what degree the host plant can influence parasite morphology (Musselman and Parker, 1982), and there is no cardinal feature that may be employed to distinguish species reliably, VOCs could be an alternative for solving taxonomical problems. For example, it is not easy to distinguish O. elatior (Figure 1A) from O. alsatica (Figure 1C) on the basis of morphological traits (Zázvorka, 2010) and the same is true for O. alsatica and O. mayeri (Figure 1D) (Piwowarczyk et al., 2014). Floral scents provide a useful tool to support species identification and clearly support the separation of these three into separate species (Figures 3, 4, and 6). Interesting is the phylogenetic location of the rare O. mayeri. O. mayeri shares its habitat preference with $O$. reticulata with which it closely groups and has an aromatic scent which explains its phylogentic placement close to the aromatic group (O. alba, O. caryophylacea) (Figure 6). But its VOCs clearly separate O. mayeri from the morphologically similar O. alsatica. The most notable compounds are methyl 3 -methylbutanoate (methyl isovalerate) and cuparene [1-methyl4-(1,2,2-trimethylcyclopentyl)-benzene)]. Both are absent in $O$. alsatica but do occur in O. mayeri. Methyl isovalerate and cuparene are also present in the floral blend of O. reticulata, $O$. alba and O. caryophylacea and absent in O. elatior which shares a clade with $O$. alsatica (Figure 6). Morphological and evolutionary proximity of O. mayeri with O. flava (Zázvorka, 1997) is also rejected by our analysis. All of this suggests that taxonomy of $O$. mayeri could be revalued. Additional support for the reliability of our approach is represented by the explicit separation of O. elatior and O. kochii (Figure 6). The host of both species is Centaurea scabiosa. For a long time, these species were considered two color morphs (yellowish and carrot-red) of $O$. elatior, but recently the existence of two taxonomically distinct species was postulated (Zázvorka, 2010; Frajman et al., 2013), which is clearly supported by our VOC analysis. Another surprising, color related, separation was found in O. flava. The VOC profiles of yellow morphs differed from red wine-color and typical (ochreous-pink) morphs. The latter two created a well-supported distinct clade (Figures 3, 4, and 6) and the distinct clustering of the yellow morph (including samples collected from different locations!) suggests the existence of a new subspecies. Majetic et al. (2007) found differences in floral VOCs of purple and white color morphs of Hesperis matronalis (Brassicaceae). They assumed that mutants (white morph) could divert compounds normally processed to form pigment to other pathways which could result in changes in type or amount of VOCs emitted. A similar mechanism may be responsible for the possible sub-species creation in O. flava. In addition to a number of minor quantitative differences in VOC amounts emitted by the two morphs, the typical morphs emit 6-methyl-5-hepten-2-ol while the yellow morph does not. This places the yellow morph of O. flava phylogeneticaly closer to O. elatior. O. elatior (Figure 1A) is yellowish and also missing 6-methyl-5-hepten-2-ol, whereas closely related carrot-red O. kochii (Figure 1B) emits this metabolite.

\section{Phylogenetic and Ecological Significance of VOC Differences}

Floral VOCs are unique features and each broomrape species has its own blend, which results in the well supported separate clustering of the species. Two VOCs, 2,3-butanediol and phytone seem to represent a synapomorphic character as they are closely connected to weediness. Particularly 2,3-butanediol and its precursor acetoin seem to be important in this respect. Whereas acetoin is a common floral VOC, 2,3-butanediol is much less often reported (Knudsen et al., 2006). Indeed, while acetoin was emitted by all broomrapes, 2,3-butanediol occurred only in the weedy species. The reduction of acetoin to 2,3-butanediol (Ryu et al., 2003) seems to represent a novel evolutionary trait in these weedy species. Interestingly, both volatile are released abundantly by plant growth-promoting rhizobacteria (Rudrappa et al., 2010). Especially 2,3-butanediol is an essential component responsible for airborne chemical signaling between rhizobacteria and plants (Ryu et al., 2003). For instance, exogenous application of 2,3butanediol to Arabidopsis thaliana seedlings promotes growth and induces systemic acquired resistance (Ping and Boland, 2004). The intriguing acquisition of 2,3-butanediol emission by the weedy broomrapes may be speculated to represent a strategy that results in improved growth of the broomrape host or the broomrape itself.

The sesquiterpene aristolene is a key feature of most Orobanche spp. Aristolene is known as floral VOC only from two families, Araceae and Nyctaginaceae (Knudsen et al., 2006). Root extracts of Valeriana jatamansi (Valerianaceae), containing $5.2 \%$ of this compound, were shown to have insecticidal activity (Dua et al., 2008). The aristolene in the flower VOC blend of the Orobanche spp. may have a similar function and protect the flowers against insect herbivory. The other compound only present in the weedy Phelipanche broomrapes is phytone. Phytone is a ubiquitous compound, occurring in plants and insects (Schulz et al., 2011). It is known for its allelopathic, antimicrobial, antifungal, and pheromonal activity (Cakir et al., 2005; Radulovic et al., 2006; Kalinová et al., 2009).

The presence of synapomorphic characters as well as the position in the HCD may help to predict potentially problematic future weedy broomrapes. O. foetida could serve as an example 
as this species became an agricultural problem just a few decades ago and before grew only on wild host plants (Rubiales et al., 2005). The floral VOCs in retrospect pre-determine O. foetida to be a weedy broomrape (Figure 6), which it indeed became. Looking to the future, O. lutea, a species with weedy volatile pattern (Figure 6), may be the next problematic species. Presently, it grows almost exclusively on the wild Medicago falcata (Piwowarczyk et al., 2011), but it could potentially become a serious weed of alfalfa and clover (Teryokhin, 1997). The clustering of B. latisquama and Ci. phelypea in the O. cumana lineage could also point to a risk that they may develop into future weeds.

The ultimate ecological relevance of flower VOCs is of course the mediation of the interaction between flowers and animal flower visitors (Raguso, 2008a). In Slovakia, the key broomrape pollinators are social wasps (Dolichovespula norwegica, D. sylvestris, Vespula rufa on O. flava, and Polistes nimpha on O. alba, O. alsatica, O. lutea), bumblebees (e.g., Bombus lucorum, B. pascuorum, B. hortorum, and B. ruderalis on O. flava, O. lutea, O. alsatica, O. elatior, O. reticulata), bees from the Halictidae and Colletidae (O. alba, O. alsatica, O. elatior, O. flava, O. reticulata, Ph. ramosa), and hoverflies (Syrphidae) (especially on O. flava). However, no social wasps and bumblebees were recorded on any weedy species. 2methylpropan-1-ol together with acetic acid and 2-methylbutan1-ol are highly attractive for wasps especially in a mixture (Landolt et al., 2007). While these three VOCs are common across the wild broomrapes (including $P h$. arenaria!) as well as in O. lutea and O. crenata that locate in the "weedy" group, 2-methylpropan-1-ol is completely missing in the other weedy broomrapes. Eucalyptol, known as the main active ingredient of the bumblebee foraging alert pheromone (Granero et al., 2005), is present in the volatile blend of all broomrapes. Nevertheless, weedy species (e.g., Ph. ramosa) are not visited by bumblebees despite the fact that they are present and for example pollinate the crop (e.g., tomato) on which these broomrapes parasitise. Except $\beta$-myrcene, $\alpha$-pinene, $\beta$-pinene, $p$-cymene, and limonene, which are present in all broomrapes, there are many other compounds that could be attractive for bees, e.g., geraniol, translinalool oxide, $\gamma$-terpinene and terpinyl acetate (Dobson, 2006; Dötterl and Vereecken, 2010) present in the volatile blend of wild species while they are absent in weedy species. The VOC blends of Phelipanche spp. contain markedly more benzenoids. Flowers of $\mathrm{Ph}$. ramosa (Figure $\mathbf{1 F}$ ) were only pollinated by sweet bees (Halictidae) and polyester bees (Colletidae). Theis (Theis, 2006) showed that sweet bees are attracted to phenylacetaldehyde, a very general insect attractant (El-Sayed et al., 2008). This VOC is very common also in Phelipanche spp. (except $P h$. arenaria/Figure $1 \mathrm{E} /$ ) but it is missing in wild broomrapes (except $O$. alba). In conclusion, the loss of pollination by social wasps and bumblebees in weedy broomrapes coincides with a change in floral VOCs. Moreover the majority of the weedy species (including O. cumana, O. crenata, O. minor) are blue or purple and these colors contribute minimally to pollinator attractiveness (Sun et al., 2005) while decreasing herbivore performance (Strauss and Whittall, 2006). On the other hand, blue and purple flowers have a higher fitness including higher rates of seed maturation in a short growing season (Whittall and Carlson, 2009) a feature vital for weedy species.

\section{CONCLUSION}

We showed that floral VOCs can to distinguish broomrape species. The life history of the host plants seems to be the driving force in the evolution within these parasitic plants. In addition, the floral VOCs clearly separated the weedy broomrapes from the wild species. This and the synapomorphic characters associated with the weediness could be of help in forecasting potential future weed problems. The reproducible character of the VOC blends could be a useful tool to support the taxonomical phylogeny of the Orobanchaceae.

\section{AUTHOR CONTRIBUTIONS}

The authors have made the following declarations about their contributions: Conceived and designed the experiments: PT, HB. Performed the experiments: PT. Analyzed the data: PT, AU. Contributed reagents/materials/analysis tools: FV. Wrote the paper: PT, HB.

\section{FUNDING}

We acknowledge funding by the European Commission (IntraEuropean Marie Curie fellowship FP7-PIEF-GA-2008-220177) to PT. PT was also supported by Scientific Grant Agency of the Ministry of Education of Slovak Republic and the Academy of Sciences (VEGA 1/0827/14).

\section{ACKNOWLEDGMENTS}

We thank Daniel M. Joel for supplying O. cernua seeds, Diego Rubiales for his help with broomrape collection in Spain, Roland Mumm for his technical advice, Jozef Lukáš for identification of pollinators and Renata Piwowarczyk for fruitful discussion about O. elatior, O. kochii, and O. mayeri taxonomy.

\section{SUPPLEMENTARY MATERIAL}

The Supplementary Material for this article can be found online at: http://journal.frontiersin.org/article/10.3389/fpls.2016.00312 


\section{REFERENCES}

Adams, R. P. (2007). Identification of Essential oil Components by Gas Chromatography/Mass Spectroscopy. Carol Stream, IL: Allured Publishing Corporation.

Barkman, T. J. (2001). Character coding of secondary chemical variation for use in phylogenetic analyses. Biochem. Syst. Ecol. 29, 1-20. doi: 10.1016/S03051978(00)00031-4

Beck-Mannagetta, G. (1930). "IV. 261. Orobanchaceae," in Das Pflanzenreich. Regni Vegetabilis Conspectus, ed. A. Engler (Leipzig: Wilhelm Engelmann), 1-348.

Bennett, J. R., and Mathews, S. (2006). Phylogeny of the parasitic plant family Orobanchaceae inferred from phytochrome A. Am. J. Bot. 93, 1039-1051. doi: 10.3732/ajb.93.7.1039

Cakir, A., Kordali, S., Kilic, H., and Kaya, E. (2005). Antifungal properties of essential oil and crude extracts of Hypericum linarioides Bosse Source. Biochem. Syst. Ecol. 33, 245-256. doi: 10.1016/j.bse.2004.08.006

Carlón, L., Gómez Casares, G., Laínz, M., Moreno Moral, G., Sánchez Pedraja, Ó., and Schneeweiss, G. M. (2005). Más, a propósito de algunas Orobanche L. y Phelipanche Pomel (Orobanchaceae) del oeste del Paleártico. Documentos Jard. Bot. Atlántico (Gijón) 3, 1-71.

Carlón, L., Gómez Casares, G., Laínz, M., Moreno Moral, G., Sánchez Pedraja, Ó., and Schneeweiss, G. M. (2008). Más, a propósito de algunas Phelipanche Pomel, Boulardia F. W. Schultz y Orobanche L. (Orobanchaceae) del oeste del Paleártico. Documentos Jard. Bot. Atlántico (Gijón) 6, 1-128.

Castillejo, M. A., Fernández-Aparicio, M., Satovic, Z., and Rubiales, D. (2009). Comparative proteomic analysis of Orobanche and Phelipanche species inferred from seed proteins. Weed Res. 49, 81-87. doi: 10.1111/j.1365-3180.2009.00747.x

Dobson, H. E. M. (2006). "Relationship between floral fragrance composition and type of pollinator," in Biology of Floral Scent, eds N. Dudareva and E. Pichersky (Boca Raton, FL: CRC Press), 147-198.

Dötterl, S., and Vereecken, N. J. (2010). The chemical ecology and evolution of bee-flower interactions: a review and perspective. Can. J. Zool. 88, 668-697. doi: 10.1139/Z10-031

Dua, V. K., Alam, M. F., Pandey, A. C., Rai, S., Chopra, A. K., Kaul, V. K., et al. (2008). Insecticidal activity of Valeriana jatamansi (Valerianaceae) against mosquitoes. J. Am. Mosquito Control. Assoc. 24, 315-318. doi: 10.2987/5642.1

Dudareva, N., Negre, F., Nagegowda, D. A., and Orlova, I. (2006). Plant volatiles: recent advances and future perspectives. Crit. Rev. Plant Sci. 25, 417-440. doi: $10.1080 / 07352680600899973$

Dudareva, N., and Pichersky, E. (2006). "Floral scent metabolic pathways: their regulation and evolution," in Biology of Floral Scent, eds N. Dudareva and E. Pichersky (Boca Raton, FL: CRC Press), 55-78.

El-Sayed, A. M. (2012). The Pherobase: Database of Insect Pheromones and Semiochemicals. Available at: http://www.pherobase.com [accessed May 17 2012].

El-Sayed, A. M., Byers, J. A., Manning, L. M., Jürgens, A., Mitchell, V. J., and Suckling, D. M. (2008). Floral scent of Canada thistle and its potential as a generic insect attractant. J. Econ. Entomol. 101, 720-727. doi: 10.1093/jee/101.3.720

Frajman, B., Carlón, L., Kosachev, P., Sánchez Pedraja, O., Schneeweiss, G. M., and Schönswetter, P. (2013). Phylogenetic position and taxonomy of the enigmatic Orobanche krylowii (Orobanchaceae), a predominantly Asian species newly found in Albania (SE Europe). Phytotaxa 137, 1-14. doi: 10.11646/phytotaxa.137.1.1

Granero, A. M., Sanz, J. M., Gonzalez, F. J., Vidal, J. L., Dornhaus, A., Ghani, J., et al. (2005). Chemical compounds of the foraging recruitment pheromone in bumblebees. Naturwissenschaften 92, 371-374. doi: 10.1007/s00114-0050002-0

Johnson, S. D., Hargreaves, A. L., and Brown, M. (2006). Dark, bitter-tasting nectar functions as a filter of flower visitors in a bird-pollinated plant. Ecology 87, 2709-2716. doi: 10.1890/0012-9658 (2006)87[2709:DBNFAA]2.0.CO;2

Junker, R. R., Hocherl, N., and Bluthgen, N. (2010). Responses to olfactory signals reflects network structure of flower-visitor interactions. J. Anim. Ecol. 79, 818-823. doi: 10.1111/j.1365-2656.2010.01698.x

Kaiser, R. (2006). Flowers and fungi use scents to mimic each other. Science 311, 806-807. doi: 10.1126/science.1119499

Kalinová, B., Kindl, J., Jiros, P., Zácek, P., Vasícková, S., Budesínský, M., et al. (2009). Composition and electrophysiological activity of constituents identified in male wing gland secretion of the bumblebee parasite Aphomia sociella. J. Nat. Prod. 72, 8-13. doi: 10.1021/np800434x

Kappers, I. F., Verstappen, F., Luckerhoff, L. P., Bouwmeester, H. J., and Dicke, M. (2010). Genetic variation in jasmonic acid- and spider mite-induced plant volatile emission of cucumber accessions and attraction of the predator Phytoseiulus persimilis. J. Chem. Ecol. 36, 500-512. doi: 10.1007/s10886-0109782-6

Knudsen, J. T., Eriksson, R., Gershenzon, J., and Stahl, B. (2006). Diversity and distribution of floral scent. Bot. Rev. 72, 1-120. doi: 10.1111/plb.12000

Knudsen, J. T., and Gershenzon, J. (2006). "The chemical diversity of floral scent," in Biology of Floral Scent, eds N. Dudareva and E. Pichersky (Boca Raton, FL: CRC Press), 27-52.

Knudsen, J. T., Tollsten, L., Groth, I., Bergström, L. G., and Raguso, R. A. (2004). Trends in floral scent chemistry in pollination syndromes: floral scent composition in hummingbird-pollinated taxa. Bot. J. Linn. Soc. 146, 191-199. doi: 10.1111/j.1095-8339.2004.00329.x

Kroschel, J. (ed.) (2001). A Technical Manual for Parasitic Weed Research and Extension. Dodrecht: Kluwer Academic Publishers.

Landolt, P. J., Toth, M., and Josvai, J. (2007). First European report of social wasps trapped in response to acetic acid, isobutanol, 2-methyl-2-propanol, and heptyl butyrate in tests conducted in Hungary. Bull. Insectol. 60, 7-11.

Levin, R. A., McDade, L. A., and Raguso, R. A. (2003). The systematic utility of floral and vegetative fragrance in two genera of Nyctaginaceae. Syst. Biol. 52, 334-351. doi: 10.1080/10635150390196975

Lommen, A. (2009). MetAlign: interface-driven, versatile metabolomics tool for hyphenated full-scan mass spectrometry data preprocessing. Anal. Chem. 81, 3079-3086. doi: 10.1021/ac900036d

Majetic, C. J., Raguso, R. A., Tonsor, S. J., and Ashman, T. L. (2007). Flower color-flower scent associations in polymorphic Hesperis matronalis (Brassicaceae). Phytochemistry 68, 865-874. doi: 10.1016/j.phytochem.2006 12.009

Manen, J. F., Habashi, C., Jeanmonod, D., Park, J. M., and Schneeweiss, G. M. (2004). Phylogeny and intraspecific variability of holoparasitic Orobanche (Orobanchaceae) inferred from plastid rbcL sequences. Mol. Phylogenet. Evol. 33, 482-500. doi: 10.1016/j.ympev.2004.06.010

Matúšová, R., van Mourik, T., and Bouwmeester, H. J. (2004). Changes in the sensitivity of parasitic weed seeds to germination stimulants. Seed Sci. Res. 14, 335-344. doi: 10.1079/SSR2004187

McNeal, J. R., Bennett, J. R., Wolfe, A. D., and Mathews, S. (2013). Phylogeny and origins of holoparasitism in Orobanchaceae. Am. J. Bot. 100, 971-983. doi: 10.3732/ajb. 1200448

Meekijjaroenroj, A., Bessière, J. M., and Anstett, M. C. (2007). Chemistry of floral scents in four Licuala species (Arecaceae). Flavour Fragr. J. 22, 300-310. doi: 10.1002/ffj.1797

Musselman, L. J., and Parker, C. (1982). Preliminary host ranges of some strains of economically important broomrapes (Orobanche). Econ. Bot. 36, 270-273. doi: 10.1007/BF02858547

Musselman, L. J., Parker, C., and Dixon, N. H. (1981). Notes on autogamy and flower structure in agronomically important species of Striga (Scrophulariaceae) and Orobanche (Orobanchaceae) root parasites. Beitr. Biol. Pflanzen. 56, 329-343.

Park, J. M., Manen, J. F., Colwell, A. E., and Schneeweiss, G. M. (2008) A plastid gene phylogeny of the non-photosynthetic parasitic Orobanche (Orobanchaceae) and related genera. J. Plant Res. 121, 365-376. doi: 10.1007/s10265-008-0169-5

Parker, C. (2009). Observations on the current status of Orobanche and Striga problems worldwide. Pest Manag. Sci. 65, 453-459. doi: 10.1002/ps.1713

Pichersky, E., and Gershenzon, J. (2002). The formation and function of plant volatiles: perfumes for pollinator attraction and defense. Curr. Opin. Plant Biol. 5, 237-243. doi: 10.1016/S1369-5266(02)00251-0

Ping, L. Y., and Boland, W. (2004). Signals from the underground: bacterial volatiles promote growth in Arabidopsis. Trends Plant Sci. 9, 263-266. doi: 10.1016/j.tplants.2004.04.008

Piwowarczyk, R., Chmielewski, P., and Cwener, A. (2011). The distribution and habitat requirements of the genus Orobanche L. (Orobanchaceae) in SE Poland. Acta Soc. Bot. Pol. 80, 37-48. doi: 10.5586/asbp.2011.006

Piwowarczyk, R., Halamski, A. T., and Durska, E. (2014). Seed and pollen morphology in the Orobanche alsatica complex (Orobanchaceae) from central 
Europe and its taxonomic significance. Aust. Syst. Bot 27, 145-157. doi: $10.1071 /$ SB14013

Piwowarczyk, R., and Krajewski, L. (2014). Orobanche lutea Baumg. (Orobanchaceae) in Poland: revised distribution, taxonomy, phytocoenological and host relations. Biodiv. Res. Conserv. 34, 17-39. doi: 10.2478/biorc-2014-0008

Press, M. C., and Phoenix, G. K. (2005). Impacts of parasitic plants on natural communities. New Phytol. 166, 737-751. doi: 10.1111/j.1469-8137.2005.01358.x

Pujadas Salva, A. J. (1997). Orobanche ballotae A. Pujadas (Orobanchaceae), a new species. Acta Bot. Malacitana 22, 29-34.

Radulovic, N., Stojanovic, G., and Palic, R. (2006). Composition and antimicrobial activity of Equisetum arvense L. Essential oil. Phytother. Res. 20, 85-88. doi: $10.1002 /$ ptr. 1815

Raguso, R. A. (2008a). Wake up and smell the roses: the ecology and evolution of floral scent. Annu. Rev. Ecol. Evol. Syst. 39, 549-569. doi: 10.1146/annurev.ecolsys.38.091206.095601

Raguso, R. A. (2008b). Start making scents: the challenge of integrating chemistry into pollination ecology. Entomol. Exp. Appl. 128, 196-207. doi: 10.1111/j.15707458.2008.00683.x

Raguso, R. A., Schlumpberger, B. O., Kaczorowski, R. L., and Holtsford, T. P. (2006). Phylogenetic fragrance patterns in Nicotiana sections Alatae and Suaveolentes. Phytochemistry 67, 1931-1942. doi: 10.1016/j.phytochem. 2006.05.038

Román, B., Alfaro, C., Torres, A. M., Moreno, M. T., Satovic, Z., Pujadas, A., et al. (2003). Genetic relationship among Orobanche species as revealed by RAPD analysis. Ann. Bot. Lon. 91, 637-642. doi: 10.1093/aob/mcg060

Rubiales, D., Sadiki, M., and Roman, B. (2005). First report of Orobanche foetida on common vetch (Vicia sativa) in Morocco. Plant Dis. 89, 528-528. doi: 10.1094/PD-89-0528A

Rubiales, D., Verkleij, J., Vurro, M., Murdoch, A. J., and Joel, D. M. (2009). Parasitic plant management in sustainable agriculture. Weed Res. 49, 1-5. doi: 10.1111/j.1365-3180.2009.00741.x

Rudrappa, T., Biedrzycki, M. L., Kunjeti, S. G., Donofrio, N. M., Czymmek, K. J., Paré, P. W., et al. (2010). The rhizobacterial elicitor acetoin induces systemic resistance in Arabidopsis thaliana. Commun. Integr. Biol. 3, 130-138. doi: 10.4161/cib.3.2.10584

Ryu, C. M., Farag, M. A., Hu, C. H., Reddy, M. S., Wei, H. X., Paré, P. W., et al. (2003). Bacterial volatiles promote growth in Arabidopsis. Proc. Natl. Acad. Sci. U.S.A. 100, 4927-4932. doi: 10.1073/pnas.0730845100

Schneeweiss, G. M. (2007). Correlated evolution of life history and host range in the nonphotosynthetic parasitic flowering plants Orobanche and Phelipanche (Orobanchaceae). J. Evol. Biol. 20, 471-478. doi: 10.1111/j.14209101.2006.01273.x

Schneeweiss, G. M., Colwell, A., Park, J. M., Jang, C. G., and Stuessy, T. F. (2004). Phylogeny of holoparasitic Orobanche (Orobanchaceae) inferred from nuclear ITS sequences. Mol. Phylogenet. Evol. 30, 465-478. doi: 10.1016/S10557903(03)00210-0

Schulz, S., Yildizhan, S., and van Loon, J. J. A. (2011). The biosynthesis of hexahydrofarnesylacetone in the butterfly Pieris brassicae. J. Chem. Ecol. 37, 360-363. doi: 10.1007/s10886-011-9939-y

Shimodaira, H. (2004). Approximately unbiased tests of regions using multistep-multiscale bootstrap resampling. Ann. Stat. 32, 2616-2641. doi: $10.1214 / 009053604000000823$
Snoeren, T. A., Kappers, I. F., Broekgaarden, C., Mumm, R., Dicke, M., and Bouwmeester, H. J. (2010). Natural variation in herbivore-induced volatiles in Arabidopsis thaliana. J. Exp. Bot. 61, 3041-3056. doi: 10.1093/jxb/erq127

Strauss, S. Y., and Whittall, J. B. (2006). "Non-pollinator agents of selection on floral traits," in Ecology and Evolution of Flowers, eds L. D. Harder and S. C. H. Barrett (New York, NY: Oxford University Press), 120-138.

Sun, S. G., Liao, K., Xia, J., and Guo, Y. H. (2005). Floral colour change in Pedicularis monbeigiana (Orobanchaceae). Pl. Syst. Evol. 255, 77-85. doi: $10.1093 / \mathrm{aob} / \mathrm{mcr} 216$

Tank, D. C., Beardsley, P. M., Kelchner, S. A., and Olmstead, R. G. (2006). Review of the systematics of Scrophulariaceae s.l. and their current disposition. Aust. Syst. Bot. 19, 289-307. doi: 10.1071/SB05009

Teryokhin, E. S. (1997). Weed Broomrapes, Systematics, Ontogenesis, Biology, Evolution. Landshut: Aufstieg-Verlag.

Teryokhin, E. S., Shibakina, G. V., Serafimovich, N. B., and Kravtsova, T. I. (1993). Opredelitelj Sarasichovich Florii SSSR (Determinator of Broomrapes of the USSR Flora). Leningrad: Nauka.

Theis, N. (2006). Fragrance of canada thistle (Cirsium arvense) attracts both floral herbivores and pollinators. J. Chem. Ecol. 32, 917-927. doi: 10.1007/s10886-0069051-x

Tikunov, Y., Lommen, A., de Vos, C. H., Verhoeven, H. A., Bino, R. J., Hall, R. D., et al. (2005). A novel approach for nontargeted data analysis for metabolomics. Large-scale profiling of tomato fruit volatiles. Plant Physiol. 139, 1125-1137. doi: $10.1104 /$ pp.105.068130

Vaz Patto, M. C., Fernández-Aparicio, M., Satovic, Z., and Rubiales, D. (2009). Extent and pattern of genetic differentiation within and between European populations of Phelipanche ramosa revealed by amplified fragment length polymorphism analysis. Weed Res. 49, 48-55. doi: 10.1111/j.13653180.2009.00740.x

Whittall, J., and Carlson, M. (2009). Plant defense: a pre-adaptation for pollinator shifts. New Phytol. 182, 5-8. doi: 10.1111/j.1469-8137.2009.02796.x

Williams, N. H., and Whitten, W. M. (1999). Molecular phylogeny and floral fragrances of male euglossine bee-pollinated orchids: a study of Stanhopea (Orchidaceae). Plant Spec. Biol. 14, 129-136. doi: 10.1046/j.14421984.1999.00016.x

Wolfe, A. D., Randle, C. P., Liu, L., and Steiner, K. E. (2005). Phylogeny and biogeography of Orobanchaceae. Folia Geobot. 40, 115-134. doi: 10.1007/BF02803229

Zázvorka, J. (1997). “Orobanchaceae vent,” in Flóra Slovenska, Vol. 2, ed. K. Goliašová (Bratislava: Veda), 460-529.

Zázvorka, J. (2010). Orobanche kochii and O. elatior (Orobanchaceae) in central Europe. Acta Musei Moraviae Sci. Biol. (Brno) 95, 77-119.

Conflict of Interest Statement: The authors declare that the research was conducted in the absence of any commercial or financial relationships that could be construed as a potential conflict of interest.

Copyright (c) 2016 Tóth, Undas, Verstappen and Bouwmeester. This is an open-access article distributed under the terms of the Creative Commons Attribution License (CC BY). The use, distribution or reproduction in other forums is permitted, provided the original author(s) or licensor are credited and that the original publication in this journal is cited, in accordance with accepted academic practice. No use, distribution or reproduction is permitted which does not comply with these terms. 